\title{
Bioactive properties and functional constituents of Hypericum androsaemum L.: A focus on the phenolic profile
}

\author{
Inés Jabeur ${ }^{\mathrm{a}, \mathrm{b}, 1}$, Flávia Tobaldini ${ }^{\mathrm{c}, \mathrm{d}, 1}$, Natália Martins ${ }^{\mathrm{a}, \mathrm{c}}$, Lillian Barros ${ }^{\mathrm{a}, \mathrm{e}}$, Ivone Martins ${ }^{\mathrm{c}}$, Ricardo C. Calhelha ${ }^{\mathrm{a}}$, \\ Mariana Henriques ${ }^{\mathrm{c}}$, Sónia Silva ${ }^{\mathrm{b}, *}$, Lotfi Achour ${ }^{\mathrm{b}}$, Celestino Santos-Buelga ${ }^{\mathrm{f}}$, Isabel C.F.R. Ferreira ${ }^{\mathrm{a}, *}$ \\ ${ }^{a}$ Mountain Research Centre (CIMO), ESA, Polytechnic Institute of Bragança, Campus de Santa Apolónia, 1172, 5300-253 Bragança, Portugal

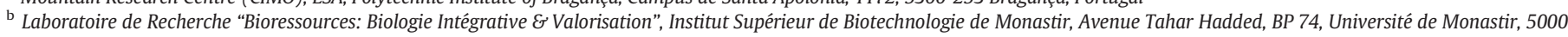 \\ Monastir, Tunisia \\ c CEB - Centre of Biological Engineering, LIBRO-Laboratório de Investigação em Biofilmes Rosário Oliveira, University of Minho, $4710-057$ Braga, Portugal \\ ' Laboratory of Medical Mycology, Department of Clinical Analysis and Biomedicine, Universidade Estadual de Maringá, Maringá, PR, Brazil

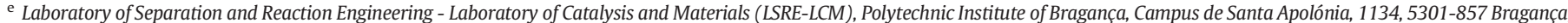 \\ Portugal \\ ${ }^{\mathrm{f}}$ Grupo de Investigación en Polifenoles (GIP-USAL), Faculty of Pharmacy, University of Salamanca, Campus Miguel de Unamuno, 37007 Salamanca, Spain
}

\section{A R T I C L E I N F O}

\section{Article history:}

Received 8 June 2016

Received in revised form 18 August 2016

Accepted 26 August 2016

Available online 28 August 2016

\section{Keywords:}

Hypericum androsaemum $\mathrm{L}$.

Antioxidant

Cytotoxic

Anti-inflammatory

Anti-Candida

Phenolic compounds

\begin{abstract}
A B S T R A C T
Hypericum androsaemum L. ethanol:water extract acted as a lipid peroxidation inhibitor and free radical scavenger. A marked inhibition of the growth of breast, lung, cervical and hepatocellular human carcinoma cell lines was also observed, whereas no toxicity was shown against non-tumor porcine liver cells ( $>400 \mu \mathrm{g} / \mathrm{mL}$ ). The extract was also effective in inhibiting nitric oxide production, as an indicator of the anti-inflammatory potential. The anti-Candida effects varied among different strains of the same species, C. glabrata and C. tropicalis being the most sensible species with an effect directly related with the extract concentrations tested. A significant antibiofilm formation potential was also observed, namely for $C$. glabrata and $C$. tropicalis (biofilm reduction $>90 \%$ ). 5-O-Caffeoylquinic and 3-O-caffeoylquinic acids were the most abundant phenolic compounds identified in the extract, and might be related with the observed bioactive effects. Nevertheless, future studies should be carried out to obtain dose-response curves of the isolated active compounds, in order to perform further preclinically testing to quantify the presence of the most active compounds in the extract.
\end{abstract}

(c) 2016 Elsevier Ltd. All rights reserved.

\section{Introduction}

Medicinal plants have been used over years for multiple purposes, and have increasingly attracted the interest of researchers in order to evaluate their contributes to health maintenance and disease's prevention (Murray and Gramercy Books, 2004). Several studies have been carried out, but numerous active principles directly responsible for the observed bioactive properties remain unknown, while in other cases the mechanism of action is not fully understood.

Hypericum species (Hypericaceae family; nearly about 450 species) are examples of these plants, being Hypericum perforatum L. the most widely known and with attributed anti-depressive, anti-inflammatory, antitumor, antimicrobial, antioxidant and antiviral benefits (Nogueira et al., 2013; Rainha, Lima, \& Baptista, 2011; Ramalhete et al., 2016). However, based on recent findings, other Hypericum species have

\footnotetext{
* Corresponding authors

E-mail addresses: soniasilva@deb.uminho.pt (S. Silva), iferreira@ipb.pt (I.C.F.R. Ferreira)

${ }^{1}$ Both authors contributed equally.
}

also revealed very interesting functional properties. Hypericum androsaemum L., commonly known as sweet-amber, has a popular use as cholagogue, hepatoprotector, nephroprotective and diuretic (Guedes, Amorim, Vicente, Ramos, \& Fernandes-Ferreira, 2003). In fact, Hypericum species are also used for culinary and cosmetic purposes and, in particular, the use of $H$. androsaemum as a spice, herbal tea and even its external application in wounds and burns (due to its healing potential) is also highly recommended (Mazandarani, Yassaghi, Rezaei, Mansourian, \& Ghaemi, 2007).

The antioxidant potential of a $H$. androsaemum aqueous extract prepared from the whole plant (Hernandez, Falé, Araújo, \& Serralheiro, 2010; Ramos, Marques, Fernandes-Ferreira, \& Pereira-Wilson, 2013), aerial parts (Rainha et al., 2011) and leaves (Valentão et al., 2002) has been described. In addition, the hepatoprotective effects of aqueous obtained from leaves have been reported, and directly correlated with their antioxidant capacity (Valentão et al., 2004). The antitumor potential of $H$. androsaemum aqueous extracts was also studied (Xavier, Lima, Fernandes-Ferreira, \& Pereira-Wilson, 2012), through the evaluation of their anti-proliferative and pro-apoptotic effects in human colorectal cancer cells. It is important to highlight that no reports have been 
found evaluating its anti-inflammatory potential, which is of utmost importance once inflammation is not only a consequence of the free radicals overproduction, but also a cause of numerous disorders, such as neurodegenerative and cardiovascular diseases, and even cancer (Valko et al., 2007). Regarding antimicrobial effects, those were only described for ethanol extracts obtained from the aerial parts (Nogueira et al., 2013). In fact, opportunistic fungal infections constitute a serious threat to human health and wellbeing (Lott, Fundyga, Kuykendall, \& Arnold, 2005), and for many years, Candida albicans has been designated as the most widespread involved opportunistic pathogenic yeast (Guinea, 2014). However, other non-C. albicans Candida (NCAC) species, such as $C$. glabrata, C. tropicalis and $C$. parapsilosis, have been already and increasingly isolated mainly due to the indiscriminate prescription of antifungal agents (Estivill, Arias, Torres-Lana, Carrillo-Munoz, \& Arevalo, 2011; Gacser, Schafer, Nosanchuk, Salomon, \& Nosanchuk, 2007; Kuhn, Chandra, Mukherjee, \& Ghannoum, 2002). More interestingly is that the pathogenesis of candidiasis is common to all Candida species and facilitated by several virulent factors (Silva et al., 2012). The major virulence factor of Candida species is its ability to adapt to a variety of different habitats, with the consequent formation of surface-attached microbial communities known as biofilms (Chandra et al., 2001; Douglas, 2003; Ganguly \& Mitchell, 2011). Therefore, the presence of persists in the Candida biofilm greatly tolerates high dose of fungicidal (Lewis, 2007), which complicates the clinical therapy for the nosocomial infections (Moran, Grussemeyer, Spalding, Benjamin, \& Reed, 2010). Thus, the assessment of the biofilm formation inhibitory potential of $H$. androsaemum may be conceived as a promissory antifungal therapy.

The composition of $\mathrm{H}$. androsaemum in terms of phenolic compounds has been analyzed by some authors, namely in aqueous (Valentão et al., 2002; Valentão et al., 2004) and methanol (Porzel, Farag, Mülbradt, \& Wessjohann, 2014; Valentão et al., 2003) extracts from leaves and aerial parts (Rainha et al., 2011; Ramalhete et al., 2016). Nevertheless, there are no studies reporting different bioactive properties (antioxidant, cytotoxic, anti-inflammatory and anti-Candida properties) in a specific extract of $H$. androsaemum (ethanol: water, $80: 20, v / v$ ), and relating them with its phenolic composition, which was carried out in the present work. The biological effects to be tested were selected based on the fact that high levels of oxidative stress promotes inflammation, as also immune system weakening, cell damages, and consequently enhances the growth of cancerous cells. Otherwise, inflammatory, infectious and also carcinogenic processes involve free radicals overproduction, which needs to be controlled. Furthermore, numerous bioactive ingredients derived from plants and other natural matrices have been increasingly applied as food ingredients, not only for organoleptic purposes but also for nutritional and even healthenhancing purposes. Therefore, the study of upcoming natural matrices may be also conceived not only as a source of effective and upcoming therapies, but also a way to discover promissory bioactive molecules for food industry and even pharmaceutical purposes.

\section{Material and methods}

\subsection{Plant material and preparation of the ethanol:water extract}

Aerial parts of Hypericum androsaemum L., namely leaves, flowers and inflorescences were provided by "Cantinho das Aromáticas", an organic and certified farm from Vila Nova de Gaia, Portugal and the botanical identification was confirmed by the botanist, Dr. Carlos Aguiar from School of Agriculture at the Polytechnic Institute of Bragança, Portugal.

The dried samples were reduced to powder and submitted to the following extraction procedure, at room temperature $\left(\sim 25^{\circ} \mathrm{C}\right)$, in three independent experiments: $4 \mathrm{~g}$ were stirred with $30 \mathrm{~mL}$ of ethanol: water $(80: 20, v / v)$ for $1 \mathrm{~h}$, filtered and re-extracted twice in the same conditions. Ethanol was removed in a rotary evaporator (Büchi R-210, Flawil, Switzerland), while water was removed by lyophilisation $\left(-48{ }^{\circ} \mathrm{C}\right.$ and 0.100 mbar, during 2-3 days, FreeZone 4.5, Labconco, Kansas City, MO,
USA). Stock solutions of the extract were prepared with water: $5 \mathrm{mg} / \mathrm{mL}$ (for antioxidant activity assays), $8 \mathrm{mg} / \mathrm{mL}$ (for antitumor and anti-inflammatory activity assays) and $50 \mathrm{mg} / \mathrm{mL}$ (for anti-Candida activity assays), from which several dilutions were performed. Different concentrations were used for each in vitro assay due to the different parameters of sensitivity, specificity and reliability of the techniques. For phenolic compounds analysis the extract $(2.5 \mathrm{mg} / \mathrm{mL})$ was filtered through a $0.45 \mu \mathrm{m}$ Whatman syringe filter and transferred to an amber HPLC vial for chromatographic injection.

\subsection{Standards and reagents}

HPLC grade acetonitrile $99.9 \%$ and analytical grade purity ethanol were from Fisher Scientific (Lisbon, Portugal). 2,2-Diphenyl-1picrylhydrazyl (DPPH) was obtained from Alfa Aesar (Ward Hill, MA, USA). Formic and acetic acids were purchased from Prolabo (VWR International, France). Trolox (6-hydroxy-2,5,7, 8-tetramethylchroman-2carboxylic acid), sulforhodamine $B$, trypan blue, trichloroacetic acid (TCA), Tris, 3-(N-Morpholino)propanesulfonic acid (MOPS) and RPMI 1640 medium were purchased from Sigma Chemical Co. (St. Louis, MO, USA). Sabouraud Dextrose Broth (SDB) and Sabouraud Dextrose Agar (SDA) were from Merck (Darmstadt, Germany). Dulbecco's modified Eagle's medium, Hank's balanced salt solution (HBSS), fetal bovine serum (FBS), L-glutamine, trypsin-EDTA, penicillin/streptomycin solution (100 U/mL and $100 \mathrm{mg} / \mathrm{mL}$, respectively), were purchased from Gibco Invitrogen Life Technologies (California, USA). RAW264.7 cells were purchased from ECACC ("European Collection of Animal Cell Culture") (Salisburg, UK), lipopolysaccharide (LPS) from Sigma and DMEM medium from HyClone. The Griess Reagent System Kit was purchased from Promega, and dexamethasone from Sigma. Water was treated in a Milli-Q water purification system (TGI Pure Water Systems, Greenville, SC, USA).

\subsection{Evaluation of the antioxidant activity}

Scavenging effects on DPPH (2,2-diphenyl-1-picrylhydrazyl) radicals (RSA): an ELX800 microplate Reader (Bio-Tek Instruments, Inc.; Winooski, VT, USA) was used to evaluate and to calculate the percentage of DPPH discolouration through the formula: $\left[\left(A_{D P P H}-A_{S}\right) / A_{D P P H}\right] 100$, where $A_{S}$ is the absorbance of the solution containing the extract solution at $515 \mathrm{~nm}$, and $A_{D P P H}$ is the absorbance of the DPPH solution (Martins, Barros, Dueñas, SantosBuelga, \& Ferreira, 2015).

Reducing power (measured by ferricyanide Prussian blue assay) (RP): through this assay the capacity to convert $\mathrm{Fe}^{3+}$ into $\mathrm{Fe}^{2+}$ was assessed, measuring the absorbance at $690 \mathrm{~nm}$ in the microplate Reader above mentioned (Martins et al., 2015).

$\beta$-carotene bleaching inhibition (CBI): was determined by the $\beta$ carotene/linoleate assay. The absorbance at zero time and after $2 \mathrm{~h}$ was measured at $470 \mathrm{~nm}$ in a spectrophotometer (AnalytikJena, Jena, Germany). The neutralization of linoleate free radicals avoids $\beta$-carotene bleaching, which was calculated by the formula: $\beta$ carotene absorbance after $2 \mathrm{~h}$ of assay / initial absorbance) $\times 100$ (Martins et al., 2015).

Lipid peroxidation inhibition (LPI): this assay was based on the ability to decrease thiobarbituric acid reactive substances (TBARS) generation in porcine brain cell homogenates, which was used as a direct indicator of the antioxidant potential of extract. The color intensity of the malondialdehyde-thiobarbituric acid (MDA-TBA) adduct was measured by its absorbance at $532 \mathrm{~nm}$ and the inhibition ratio (\%) was calculated using the following formula: $[(A-B) /$ A] $\times 100 \%$, where $A$ and $B$ were the absorbance of the control and the extract solution, respectively (Martins et al., 2015). 
For all antioxidant assays three independent experiments were carried out and the results were expressed as $\mathrm{EC}_{50}$ values, which correspond to the extract concentration providing $50 \%$ of antioxidant activity or 0.5 of absorbance in the reducing power assay. Trolox was used as positive control.

\subsection{Evaluation of the cytotoxic activity}

\subsubsection{In human tumor cell lines}

In order to perform a complete in vitro cytotoxicity screening, four human tumor cell lines were selected: HeLa (cervical carcinoma), HepG2 (hepatocellular carcinoma), MCF-7 (breast adenocarcinoma) and NCI-H460 (non-small cell lung cancer), being among the most representative carcinoma cell lines. In all cases the cell lines were plated in 96well plates, with a final density of $1.0 \times 10^{4}$ cells/well, and were allowed to attach for $24 \mathrm{~h}$. Then, various extract concentrations were added to the cells and incubated during $48 \mathrm{~h}$. Afterwards, cold trichloroacetic acid (TCA $10 \%, 100 \mu \mathrm{L}$ ) was used in order to bind the adherent cells and further incubated for $60 \mathrm{~min}$ at $4{ }^{\circ} \mathrm{C}$. After the incubation period, the plates were washed with deionised water and dried, and sulforhodamine B solution (SRB $0.1 \%$ in $1 \%$ acetic acid, $100 \mu \mathrm{L}$ ) was added to each plate well and incubated for $30 \mathrm{~min}$ at room temperature. Then, the plates were washed with acetic acid (1\%) in order to remove the unbound SRB and air dried, the bounded SRB was solubilised with Tris $(10 \mathrm{mM}, 200 \mu \mathrm{L})$ and the absorbance was measured at $540 \mathrm{~nm}$ using an ELX800 microplate reader (Bio-Tek Instruments, Inc.; Winooski, VT, USA) (Abreu et al., 2011).

\subsubsection{In non-tumor porcine liver cells (PLP2)}

Liver tissues were rinsed in Hank's balanced salt solution containing $100 \mathrm{U} / \mathrm{mL}$ of penicillin and $100 \mu \mathrm{g} / \mathrm{mL}$ of streptomycin, and then divided into $1 \times 1 \mathrm{~mm}^{3}$ explants. Some of these explants were placed in $25 \mathrm{~cm}^{3}$ tissue flasks, containing DMEM and supplemented with $10 \%$ fetal bovine serum, $2 \mathrm{mM}$ of non-essential amino acids, $100 \mathrm{U} / \mathrm{mL}$ of penicillin and $100 \mathrm{mg} / \mathrm{mL}$ of streptomycin, and then incubated at $37^{\circ} \mathrm{C}$ with a humidified atmosphere containing $5 \% \mathrm{CO}_{2}$. This medium was changed every 2 days, and the cells cultivation continued under direct monitoring every 2-3 days using a phase contrast microscope. Prior to confluence, cells were sub-cultured and plated in 96-well plates, with a final density of $1.0 \times 10^{4}$ cells/well and cultivated in DMEM medium, containing $10 \% \mathrm{FBS}, 100 \mathrm{U} / \mathrm{mL}$ of penicillin and $100 \mu \mathrm{g} / \mathrm{mL}$ of streptomycin (Abreu et al., 2011). Then, cells were treated for $48 \mathrm{~h}$ with the different diluted sample solutions. Three independent experiments were carried out and the results were expressed in $\mathrm{GI}_{50}$ values, i.e. the extract concentration that inhibited $50 \%$ of the net cell growth. Ellipticine was used as positive control.

\subsection{Evaluation of the anti-inflammatory activity}

The mouse macrophage-like cell line RAW264.7 was cultured in DMEM medium, supplemented with $10 \%$ heat-inactivated fetal bovine serum and L-glutamine, at $37{ }^{\circ} \mathrm{C}$ under $5 \% \mathrm{CO}_{2}$, in humidified air. Cells were detached with a cell scraper, the experimental cell density established in $5 \times 10^{5}$ cells/ $\mathrm{mL}$ and the proportion of cell dead lesser than $1 \%$, according to Trypan blue dye exclusion tests. Then, cells were seeded in 96-well plates at 150.000 cells/well and their attachment to the plate allowed overnight. Afterwards, cells were treated with different concentrations of the extract for $1 \mathrm{~h}$. The next step consisted in the stimulation with LPS $(1 \mu \mathrm{g} / \mathrm{mL})$ for $18 \mathrm{~h}$, and the effect of the tested extracts in the absence of LPS was also assessed. To the negative controls no LPS was added. Through this procedure it was possible to observe the occurrence of induced changes in NO basal levels. For that, the tested sample and LPS were dissolved in supplemented DMEM, and nitric oxide content was determined using a Griess Reagent System kit (Promega) containing sulfanilamide, NED and nitrite solutions. One hundred microliters of the cell culture supernatant were transferred to the plate and mixed with sulfanilamide and NED solutions, for 5-
$10 \mathrm{~min}$, at room temperature. Nitrite level produced was determined by measuring optical density at $515 \mathrm{~nm}$, in a microplate reader, and then compared with the standard calibration curve. Dexamethasone $(50 \mu \mathrm{M})$ was used as positive control. Three independent experiments were carried out and the results were expressed in $\mathrm{EC}_{50}$ values, i.e. the extract concentration that inhibited $50 \%$ of the NO production.

\subsection{Evaluation of the anti-Candida activity}

\subsubsection{Yeast strains}

Eight Candida strains belonging to the species C. albicans, C. glabrata, C. parapsilosis and C. tropicalis were used in this study. Four of them were from the American Type Culture Collection (ATCC), namely C. albicans ATCC 90028, C. glabrata ATCC 2001, C. parapsilosis ATCC 22019 and C. tropicalis ATCC 750, while the other four were clinical isolates from the archive collection of the Laboratory of Medical Mycology, Universidade Estadual de Maringá, Brazil. In each experiment, Candida strains were sub-cultured overnight in SDA or SDB, at $37^{\circ} \mathrm{C}$, and then cellular density adjusted using a Neubauer chamber.

\subsubsection{Effect on Candida planktonic cells}

A) Minimal inhibitory concentration (MIC)

The antifungal activity of the $H$. androsaemum ethanol:water extract was determined by the broth microdilution method according to CLSI standard M27-A3 (Clinical and Laboratory Standards Institute, 2008), with some modifications as described for natural products (DalbenDota et al., 2010). For this, serial dilutions were performed at a ratio of 2 , from $1: 2$ to $1: 1024$. In this way, the concentrations tested of the extract ranged from 0.02 to $12.5 \mathrm{mg} / \mathrm{mL}$. The test was carried out in RPMI 1640 with L-glutamine (with sodium bicarbonate) and $0.165 \mathrm{M}$ 3-(N-morpholino)-propanesulfonic acid (pH 7.2) as buffer, supplemented with $2 \%$ glucose, in 96-well flat-bottomed microtiter plates (Orange Scientific, Braine-l' Alleud, Belgium). After incubation at $37{ }^{\circ} \mathrm{C}$ for $24 \mathrm{~h}$, MIC were determined by direct observation. After visualization of the resultant plate, the MIC values were determined as the antifungal concentration where there was no growth or even fungistatic effect, by comparison with the control (cells grown without extract). Then, the number of cultivable cells was assessed by the determination of number of colony forming units (CFUs), through several dilutions. After $24 \mathrm{~h}$ of incubation at $37^{\circ} \mathrm{C}$, the number of colonies formed was counted. The results were presented as total CFUs (log CFUs) and the experiments repeated in triplicate on three different occasions.

\section{B) Time-kill curve determination}

Time kill curves were performed for the four Candida reference strains, C. albicans ATCC 90028, C. glabrata ATCC 2001, C. parapsilosis ATCC 22019 and C. tropicalis ATCC 750 with slight modifications to that previously described (Klepser, Wolfe, Jones, \& Nightingale, 1997). Prior to testing, fungi were subcultured on SDA and the inoculum adjusted to $1-5 \times 10^{5}$ yeasts/mL, in RPMI 1640 medium, using a Neubauer chamber. Then, each Candida strain suspension was grown in the presence of the $H$. androsaemum ethanol:water extract at a concentration of $25 \mathrm{mg} / \mathrm{mL}$. The RPMI 1640 medium without plant extract was used as a positive control. Test suspensions were placed on a shaker and incubated at $37^{\circ} \mathrm{C}$. At predetermined time points $(0,1,2,4,6,8,12$, and $24 \mathrm{~h})$, serial dilutions were performed on SDA for colony-forming units (CFU) determination. Following incubation at $37{ }^{\circ} \mathrm{C}$ for $24 \mathrm{~h}$, the number of CFU was determined.

\section{C) Cell membrane lesion determination}

Flow cytometry analyses using propidium iodide (PI; Sigma) were performed to determine the effect of the H. androsaemum ethanol:water 
extract on integrity of the Candida cells membrane. For that, Candida cells $\left(10^{6}\right.$ cells $\left./ \mathrm{mL}\right)$ were incubated with the $H$. androsaemum ethanol:water extract at a concentration of $25 \mathrm{mg} / \mathrm{mL}$ for $4 \mathrm{~h}$ as described for time kill curve procedure. After this time, the cells were washed once with PBS and then stained with $1 \mu \mathrm{g} \mathrm{PI} / \mathrm{mL}$ for $30 \mathrm{~min}$. The cells were rinsed again with PBS and finally resuspended in $200 \mu \mathrm{L}$ for flow cytometry analysis using EC800 ${ }^{\mathrm{TM}}$ flow cytometer analyzer (Sony Biotechnology). Scattergram analyses were performed to evaluate morphological changes (size and complexity) and a total of 2000 events were accounted. The percentage of stained cells at FL3 (620 nm, red), representing cells with severe lesions of the membrane, was quantified.

\subsubsection{Effect on Candida biofilms}

A) Biofilm formation

In order to evaluate the effect of $H$. androsaemum ethanol:water extract on Candida species' biofilm formation, the extract was added at the beginning of their formation. For that, Candida cells were grown on SDA for $24 \mathrm{~h}$ at $37^{\circ} \mathrm{C}$, then inoculated in SDB and incubated for $18 \mathrm{~h}$ at $37^{\circ} \mathrm{C}$ under agitation at $120 \mathrm{rpm}$. After incubation, cells were harvested by centrifugation at $3000 \mathrm{~g}$ for $10 \mathrm{~min}$, at $4{ }^{\circ} \mathrm{C}$, and washed twice with $15 \mathrm{~mL}$ of phosphate-buffered saline (PBS; pH 7; $0.1 \mathrm{M}$ ). Volumes of $100 \mu \mathrm{L}$ of extract $(2 \times$ final concentration $)$ in RPMI 1640 medium were added to each well of microtiter plates. Subsequently, $100 \mu \mathrm{L}$ of standardized yeast cell suspension $\left(2 \times 10^{5}\right.$ yeasts $\left./ \mathrm{mL}\right)$ was added and plates were incubated at $37{ }^{\circ} \mathrm{C}$ on a shaker at $120 \mathrm{rpm} / \mathrm{min}$ for $24 \mathrm{~h}$ to allow biofilm formation. The extract concentrations used in this study ( $12.5 \mathrm{mg} / \mathrm{mL}$ and $25 \mathrm{mg} / \mathrm{mL}$ ) were based on our previous findings of antimicrobial susceptibility. Negative controls $(200 \mu \mathrm{L}$ of only RPMI 1640 medium) were also included.

Biofilms were analyzed by CFUs determination. For that, after $24 \mathrm{~h}$ the total medium was removed and the biofilms washed once with $200 \mu \mathrm{L}$ of PBS. Then, the biofilms were scraped from the respective wells and the suspensions vigorously vortexed for approximately 2 min to disaggregate cells from the matrix (Alves et al., 2014). Serial dilutions were made in PBS, plated onto SDA and incubated for $24 \mathrm{~h}$ at $37^{\circ} \mathrm{C}$. The results were presented in terms of log CFUs.

\subsection{Analysis of phenolic compounds}

HPLC (Hewlett-Packard 1100, Agilent Technologies, Santa Clara, USA) was used to determine phenolic composition of the extract in the conditions previously described (Barros et al., 2012). Double online detection was carried out in a diode array detector (DAD) using $280 \mathrm{~nm}$ and $370 \mathrm{~nm}$ as preferred wavelengths and in a mass spectrometer (MS) connected to the HPLC system via the DAD cell outlet. Phenolic compounds were identified by comparing their retention time, UV-vis and mass spectra with those obtained from standard compounds, when available. Otherwise, peaks were tentatively identified comparing the obtained information with available data reported in the literature. For quantitative analysis, a calibration curve $(1-100 \mu \mathrm{g} / \mathrm{mL})$ for each available phenolic standard was constructed based on the UV signal: chlorogenic acid ( $\left.\mathrm{y}=304.25 \mathrm{x}-248.06 ; R^{2}=0.999\right)$; protocatechuic acid $\left(\mathrm{y}=258.17 \mathrm{x}+328.45 ; R^{2}=0.998\right) ; p$-coumaric acid $(\mathrm{y}=$ $\left.706.09 \mathrm{x}+1228.1 ; R^{2}=0.999\right) ;$ epicatechin $(\mathrm{y}=163.23 \mathrm{x}+39.586$; $\left.R^{2}=0.999\right)$; naringenin $\left.\mathrm{y}=539.98 \mathrm{x}+161.46 ; R^{2}=0.999\right)$; taxifolin ( $\left.\mathrm{y}=224,31 \mathrm{x}+148,41 ; R^{2}=0.999\right)$, and quercetin-3-O-glucoside $\left(\mathrm{y}=336.36 \mathrm{x}+358.06 ; R^{2}=0.998\right)$. For the identified phenolic compounds for which no commercial standard was available, the quantification was performed using the calibration curve of another similar compound. Analyses were carried out in triplicate and the results were expressed in mg per $\mathrm{g}$ of dried extract.

\subsection{Statistical analysis}

All statistical tests were performed using IBM SPSS Statistics for Windows, version 22.0. (IBM Corp., Armonk, NY, USA), and the means were compared using Tukey's honestly significant difference (HSD) multiple comparisons test and further coupled to Welch to verify the equality.

\section{Results and discussion}

\subsection{Antioxidant activity}

Free radicals, among them reactive oxygen species (ROS), play an important role as triggers in a wide variety of diseases, such as (neuro)degenerative and metabolic disorders, and even cancer (Fernandez-Panchon, Villano, Troncoso, \& Garcia-Parrilla, 2008; Li et al., 2014). Numerous studies have been addressed to discover effective antioxidant compounds, their active concentrations and related modes of action, being currently considered one of the highest hot topics among the scientific community (Dato et al., 2013; Espín, García-Conesa, \& Tomás-Barberán, 2007). In fact, a relation between premature aging, longevity impairment and oxidative stress status is known to exist, although despite the intensive investigation a general consensus was not established (Halliwell, 2012). On this field, phenolic compounds seem to be promissory antioxidant agents (Carocho \& Ferreira, 2013; Fernandez-Panchon et al., 2008). Thus, and aiming to put forward alternative sources of phenolic compounds, the antioxidant potential of the $H$. androsaemum ethanol:water extract was evaluated using four different in vitro assays. The results are given in Table 1. The most relevant effect was observed in the LPI assay, followed by RSA, RP and CBI assays, which means that compounds present in the studied $H$. androsaemum extract act mainly as lipid peroxidation inhibitors. Valentão et al. (2004) also concluded that the hepatoprotective effects of $H$. androsaemum mainly derived from its strong ability to inhibit lipid peroxidation, which was in part attributed to its phenolic composition. The authors achieved a concentration-dependent $(16,62$ and $250 \mu \mathrm{g} / \mathrm{mL}$ ) effective inhibition of lipid peroxidation, by measuring the levels of MDA equivalents. However, at the highest concentration, the obtained result was not so good as the positive control. Other authors also reported radical scavenging effects when assessing the antioxidant capacity of the H. androsaemum extract. Thus, Rainha et al. (2011) working with aqueous extracts from the aerial parts of different Hypericum species, concluded that $H$. androsaemum not only exerted a strong free

Table 1

In vitro antioxidant, cytotoxic and anti-inflammatory properties of the $H$. androsaemum ethanol:water extract (mean $\pm \mathrm{SD}$ ).

\begin{tabular}{|c|c|c|}
\hline & H. androsaemum & $\begin{array}{l}\text { Positive } \\
\text { control }^{\text {a }}\end{array}$ \\
\hline \multicolumn{3}{|l|}{ Antioxidant activity $\left(\mathrm{EC}_{50}, \mu \mathrm{g} / \mathrm{mL}\right)$} \\
\hline DPPH scavenging activity (RSA) & $96 \pm 3$ & $41 \pm 1$ \\
\hline Reducing power (RP) & $103 \pm 1$ & $41 \pm 2$ \\
\hline$\beta$-carotene bleaching inhibition (CBI) & $155 \pm 5$ & $18 \pm 1$ \\
\hline TBARS inhibition (LPI) & $36 \pm 1$ & $23 \pm 1$ \\
\hline \multicolumn{3}{|l|}{ Cytotoxic activity ( $\mathrm{GI}_{50}$ values, $\mu \mathrm{g} / \mathrm{mL}$ ) } \\
\hline MCF-7 (breast carcinoma) & $106 \pm 11$ & $0.91 \pm 0.04$ \\
\hline NCI-H460 (non-small cell lung cancer) & $215 \pm 13$ & $1.0 \pm 0.1$ \\
\hline HeLa (cervical carcinoma) & $205 \pm 18$ & $1.9 \pm 0.1$ \\
\hline HepG2 (hepatocellular carcinoma) & $100 \pm 7$ & $1.1 \pm 0.2$ \\
\hline \multicolumn{3}{|l|}{ Hepatotoxicity $\left(\mathrm{GI}_{50}\right.$ values, $\left.\mu \mathrm{g} / \mathrm{mL}\right)$} \\
\hline PLP2 & $>400$ & $3.2 \pm 0.2$ \\
\hline \multicolumn{3}{|c|}{ Anti-inflammatory activity ( $\mathrm{EC}_{50}$ values, $\mu \mathrm{g} / \mathrm{mL}$ ) } \\
\hline NO production inhibition & $179 \pm 17$ & $16 \pm 1$ \\
\hline
\end{tabular}

a Positive controls, trolox, ellipticine and dexamethasone, were used for antioxidant, cytotoxic and anti-inflammatory activity assays, respectively. $\mathrm{EC}_{50}$ values correspond to the extract concentration achieving $50 \%$ of antioxidant/anti-inflammatory activity or 0.5 of absorbance in reducing power assay. $\mathrm{GI}_{50}$ values correspond to the extract concentration achieving $50 \%$ of growth inhibition in human tumor cell lines or in liver primary culture PLP2. 
radical scavenging activity but also significant inhibitory effects against linoleic acid oxidation. In the same line, Valentão et al. (2002) evaluating the antioxidant potential of aqueous extracts prepared from $H$. androsaemum leaves, described their action as strong scavengers of reactive oxygen species, mainly superoxide radicals $\left(\mathrm{IC}_{50}=\right.$ $2.9 \mu \mathrm{g} / \mathrm{mL}$ ). Similar radical scavenging effects of $H$. androsaemum aqueous extracts were also described by Hernandez et al. (2010) and Ramos et al. (2013); these latter also reported a significant ability to repair DNA damages. By comparing these results with those previously cited, it is clearly evident that the geographic origin of plant species and solvent extraction, among many other factors, exert a direct and determinant effect on its chemical composition, and consequently biological potential. Interestingly, all the previous cited authors correlated the observed biological effects with the chemical composition of $H$. androsaemum extract, namely with its abundance in phenolic compounds. Chlorogenic acids have been mentioned as the most abundant phenolic acids present in this extract (nearly 60\%) (Hernandez et al., 2010; Rainha et al., 2011; Ramos et al., 2013; Valentão et al., 2002; Valentão et al., 2004), and therefore responsible for the observed antioxidant potential. Additionally, and not least important to emphasize, is that quercetin derivatives, although present in small extent, may also contribute for the final biological potential. Hence, $H$. androsaemum may be considered a source of bioactive molecules, especially phenolic compounds, with antioxidant potential and could act as reducing agents, hydrogen donators, singlet oxygen quenchers, peroxynitrites, superoxide, hydroxyl and peroxyl radical's scavengers.

\subsection{Cytotoxic activity in tumor and non-tumor cells}

No toxicity was observed for non-tumor porcine liver cells (PLP2) at concentrations up to $400 \mu \mathrm{g} / \mathrm{mL}$ of the studied $H$. androsaemum extract, in contrast with the high hepatotoxicity registered for the positive control ellipticine (Table 1). However, the extract was able to inhibit different human tumor cell lines: breast (MCF-7), non-small cell lung (NCIH460), cervical (HeLa) and hepatocellular (HepG2) carcinoma, although relatively high concentrations were required (Table 1 ). Hepatocellular carcinoma cells $\left(\mathrm{GI}_{50}=100 \pm 7 \mu \mathrm{g} / \mathrm{mL}\right)$ were the most susceptible to the $H$. androsaemum extract, followed by breast $\left(\mathrm{GI}_{50}=106 \pm 11 \mu \mathrm{g} / \mathrm{mL}\right)$, cervical $\left(\mathrm{GI}_{50}=205 \pm 13 \mu \mathrm{g} / \mathrm{mL}\right)$ and nonsmall cell lung $\left(\mathrm{GI}_{50}=215 \pm 13 \mu \mathrm{g} / \mathrm{mL}\right)$ carcinoma cell lines. The obtained results could be due to the diversity and the occurrence of synergistic reactions between the different bioactive compounds present in the extract. In addition, it is also important to note that despite the obtained results were not highly promising when compared with the positive control ellipticine, this compound was also highly toxic for non-tumor cells at very low concentrations. As previously mentioned, the origin of the extract as well as the type of the extraction solvent may interfere with the final observed effects. For example, Xavier et al. (2012) reported the in vitro anti-proliferative and pro-apoptotic effects of $H$. androsaemum aqueous extracts in human colon carcinoma-derived cell lines, and described an $\mathrm{IC}_{50}$ concentration of $65 \mu \mathrm{g} / \mathrm{mL}$. Chlorogenic acid was the most abundant phenolic compound in the extract studied by these authors, $54 \mu \mathrm{g} / \mathrm{mg}$ (Xavier et al., 2012), which is in agreement with the herein tested ethanol: water extract, where two chlorogenic acids, 5-O-caffeoylquinic acid and 3-O-caffeoylquinic acid were the majority compounds. Thus, it seems that chlorogenic acids could be the main responsible bioactive compounds for the observed cytotoxic potential. Notwithstanding, the authors clearly emphasized that the observed effect was not due to the presence of chlorogenic acid alone, once using a concentration 20 times higher than the one present in the extract, no positive effects were observed.

\subsection{Anti-inflammatory activity}

Inflammation is in the origin of numerous degenerative and metabolic disorders, among which the most tremendous is cancer.
Notwithstanding, the inflammatory process is a very complex process, and in most of the cases the triggering factor cannot be identified, although free radicals overproduction might be one of the reasons (Aruoma, 2003; Soobrattee, Neergheen, Luximon-Ramma, Aruoma, \& Bahorun, 2005). Thus, and considering the observed antioxidant potential of the $H$. androsaemum ethanol: water extract, their antiinflammatory activity was also evaluated. A 50\% inhibition of nitric oxide (NO) production was observed at $178.78 \pm 16.60 \mu \mathrm{g} / \mathrm{mL}$ (Table 1). As far as we know, this would be the first report on the anti-inflammatory potential of $H$. androsaemum extracts. Considering the obtained results, and the fact that the phenolic composition may largely determine the observed effects, it is possible to infer that chlorogenic acids apart from displaying a significant antioxidant effect also contributes to ameliorate the inflammatory processes. In fact, it has been reported that substances with significant antioxidant properties, also exert anti-inflammatory effects. For example, Chen \& Kang (2013) assessing the in vitro anti-inflammatory and antioxidant effects of Capsicum annuum L. (red pepper) observed a direct correlation between antioxidant and anti-inflammatory effects, and that these effects are directly dependent on its phenolic composition, namely in chlorogenic and $p$-coumaric acids, which were respectively, the most abundant phenolic compounds present. In addition, the authors also observed considerable differences between the extracts obtained from the pericarp, placenta and stalks, providing the last one the highest potential (Chen \& Kang, 2013). On the other hand, Correia et al. (2005) aiming to evaluate the antioxidant potential of Equisetum telmateia Ehrh. and to determine its phenolic composition, observed that the content in proanthocyanidins was high, being then isolated for further evaluation. Moreover, and not least important to highlight was that proanthocyanidins were identified in this matrix for the first time by these authors, in particular propelargonidins, which probably explains the pronounced anti-inflammatory and antimicrobial effects of this plant, apart from its significant antioxidant potential (Correia, González-Paramás, Amaral, Santos-Buelga, \& Batista, 2005). In our study, the contents of procyanidins were lower than those observed by Correia et al. (2005) in ethyl acetate fractions; but ethanol: water extracts are considered safer and "greener" options.

\subsection{Anti-Candida activity}

\subsubsection{Effect on Candida planktonic cells}

A) Minimal inhibitory concentrations

As it can be observed in Fig. 1 (I), the extract was active against all the tested strains, with MIC values ranging from 1.56 to $12.5 \mathrm{mg} / \mathrm{mL}$. Fig. 1 (II) shows the number of counts $(\log \mathrm{CFU} / \mathrm{mL})$ for the susceptible Candida strains treated with the extract. The most pronounced fungistatic effect was observed against C. glabrata (Fig. 1(II) D) and C. parapsilosis (Fig. 1(II) C), for which the two assayed strains were sensitive with an observed effect that was directly related to the concentration tested. Variable effects were observed between each of the two strains in the other two Candida species considered. There are no doubts that both morphological and structural factors specific of each of the tested Candida species may explain the observed results, but it is also important to emphasize the different susceptibilities of Candida species, i.E. candida species with high evidences of drug-resistance (such as Candida tropicalis strains) should normally display a low sensibility to the tested plant extract. In fact, this effect was observed, but the magnitude of growth inhibition was dependent to the concentration used. By comparing the obtained results with the positive control, fluconazole, they were not really promissory, being the MIC values to $C$. albicans ATCC 90028, C. glabrata ATCC 2001, C. parapsilosis ATCC 22019 and C. tropicalis ATCC 750, respectively, 0.125, 8, 0.5 and $0.5 \mu \mathrm{g} / \mathrm{mL}$. However, it is important to point out that in this case a pure compound was used, while in the natural extract are present a rich pool of 
I

\begin{tabular}{ccc}
\hline Strains & Source & $\begin{array}{c}\text { MIC } \\
(\mathrm{mg} / \mathrm{ml})\end{array}$ \\
\hline C. albicans & Blood & 6.25 \\
Ca555 & Reference & 12.5 \\
ATCC 90028 & Urine & \\
C. parapsilosis & Reference & 3.12 \\
Cp574 & & 6.25 \\
ATCC 22019 & Vaginal secretion & 6.25 \\
C. tropicalis & & \\
Ct514423 & Reference & 3.12 \\
ATCC 750 & & 6.25 \\
C. glabrata & Urine & 1.56 \\
Cg552 & Reference & \\
ATCC 2001 & & \\
\hline & &
\end{tabular}

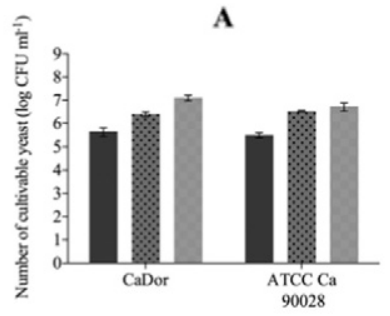

$\mathbf{A}$

II

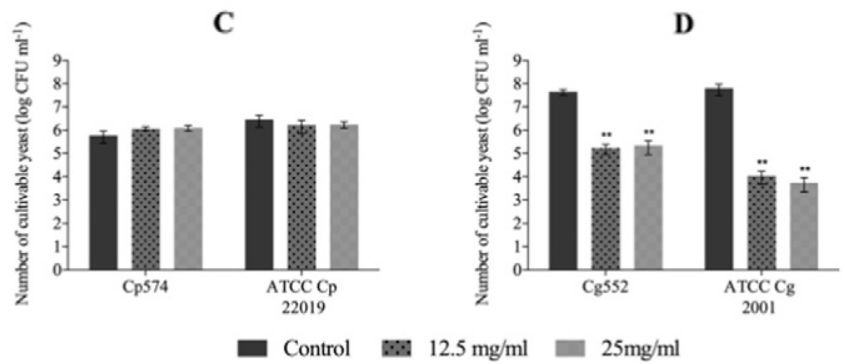

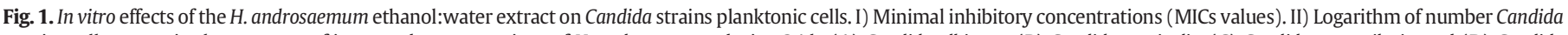

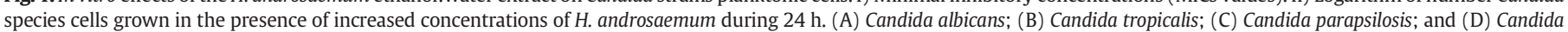
glabrata. Error bars represent standard deviation. Statistical $p$ value (represented by ${ }^{*}$ or ${ }^{* *}$ ) indicates concentrations that are significantly different from control. ${ }^{*} p<0.05$; ${ }^{* *} p<0.01$.

phytochemicals with different potentialities, being therefore of the utmost importance to access its effect both individually and mixtures of several of those compounds, as well as its synergic potential with the conventional drugs. Furthermore, it is also crucial to note that the chemical composition of the teste plant extract largely determines its biological potential; thus, and considering that 5-O-caffeoylquinic acid followed by 3-O-caffeoylquinic acid were the most abundant phenolic compounds present in the $H$. androsaemum ethanol:water extract, the observed anti-Candida effect may be directly related by its abundance at the concentrations tested.

B) Time-kill curve determination

The killing activity of the $H$. androsaemum ethanol:water extract, plotted from log CFU/mL versus time ( $24 \mathrm{~h}$ ), is represented in Fig. 2. Analysis of the time-kill curves showed an inhibitory effect against three of the tested species, C. tropicalis, C. parapsilosis and C. glabrata. At a concentration of $25 \mathrm{mg} / \mathrm{mL}$ of extract, a substantial timedependent reduction in the number of cultivable cells was observed compared with the control group. The more pronounced effect was observed in C. glabrata, with a decrease $\geq 99 \%$ of the cells ( $2.2 \operatorname{logs}$ ) at $24 \mathrm{~h}$, comparatively to control group. For the C. tropicalis and C. parapsilosis strains the reduction was about $90 \%(1.5 \mathrm{log})$ up to $12 \mathrm{~h}$ with a prominent re-growth after that time. However, no effects were observed on the pattern growth of $C$. albicans. The highest MIC value for the extract was also obtained in this species compared with $C$. tropicalis, C. parapsilosis and C. glabrata.

C) Cell membrane disruption

Flow cytometry analyses were used to investigate the effect of the $H$. androsaemum ethanol:water extract on the membrane integrity of fungal cells. PI is a nucleic acid-binding fluorescent probe commonly employed to evaluate the effect of drugs on cell membranes. Cells with severe membrane lesions leading to inherent loss of viability will internalize PI, resulting in an increase in red fluorescence (Pina-Vaz et al., 2001). The PI penetration in yeast cells treated with the extract is summarized in Fig. 3. After incubation periods of $4 \mathrm{~h}$ with $25 \mathrm{mg} / \mathrm{mL}$ of the extract, Candida cells were affected in a different manner.
Interestingly, the extract was able to disintegrate cell membranes of C. glabrata and C. tropicalis more than to the other species, whereas no significant differences between C. albicans, C. parapsilosis and control were observed (Fig. 3). The obtained results are in accordance with the observations made both on the Candida cells growth inhibition (Fig. 1) and time-kill curve assays (Fig. 2). These data indicate that C. tropicalis and C. glabrata cells are more sensitive to the treatment with $H$. androsaemum evidencing high membrane permeability when compared to untreated cells. In addition, the involved mechanisms of the antimicrobial potential conferred by the main phenolic compounds present in $H$. androsaemum remain poorly characterized.

\subsubsection{Effect on Candida biofilms}

Biofilms are structured communities that can cause serious medical problems, such as indwelling device-related infections. Recent data show that over $65 \%$ of all hospital infections derived from biofilms (Azevedo et al., 2014). Biofilm-associated Candida cells are resistant to a wide spectrum of available antifungal drugs (Ramage, Mowat, Jones, Williams, \& Lopez-Ribot, 2009). This scenario has exacerbated by the increasing demand for safer and more effective antifungal therapies, and the search for new and better agents that target fundamental biological processes and/or pathogenic determinants (Khan, Ahmad, Cameotra, \& Botha, 2014).

As presented in Fig. 4, Candida strains biofilm formation was attenuated in the presence of the $H$. androsaemum extract in the cases of C. tropicalis and C. glabrata, for which a reduction $>90 \%$ of the cultivable cells was observed on the biofilms treated with the extract at concentrations of 12.5 and $25 \mathrm{mg} / \mathrm{mL}$. Candida glabrata strains presented the highest biofilm reduction ( 2.4 to 4.1 log units) (Fig. 4D), followed by C. tropicalis with a reduction around $\sim 1$ to $3 \log$ units (Fig. 4B) compared with the control group. No significant differences were observed for C. albicans and $C$. parapsilosis biofilms in relation to the untreated biofilms (Fig. 4A and C). The results obtained for C. glabrata and C. tropicalis seem to be promising, once species NCAC exhibit more resistance to conventional antifungals. Moreover, C. glabrata are intrinsically resistant to fluconazole and other azoles, the most commonly used drugs to treat Candida infections.

Despite the weaker results in comparison with the positive controls used, the obtained data may also open new perspectives to discover more effective and safer antifungal drugs, considering that the majority 

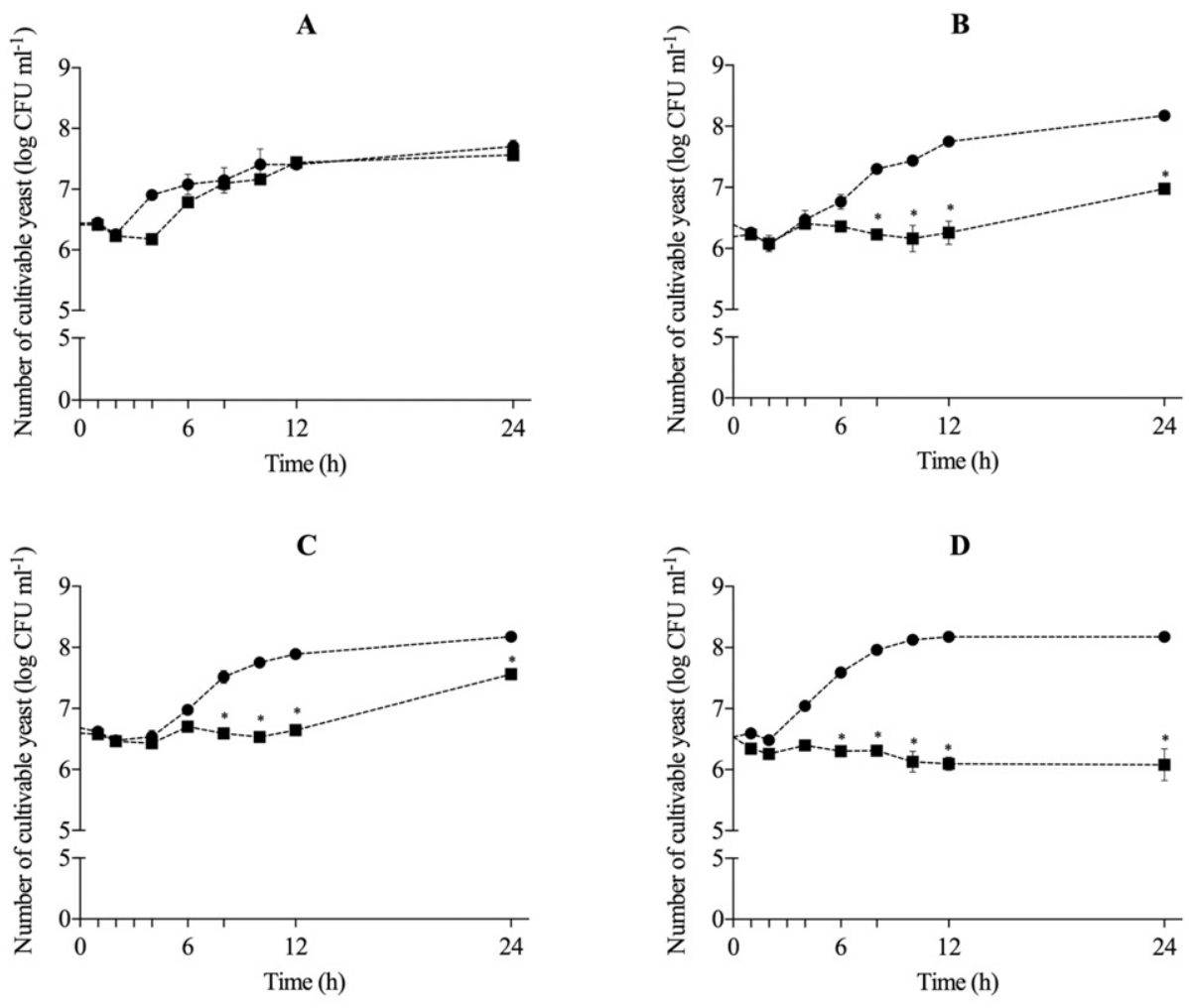

Control

$25 \mathrm{mg} / \mathrm{ml}$

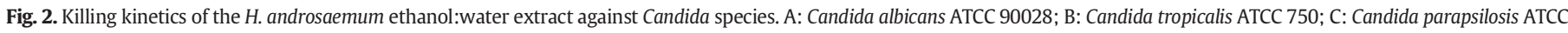

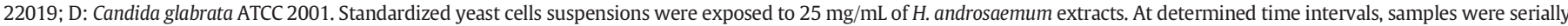

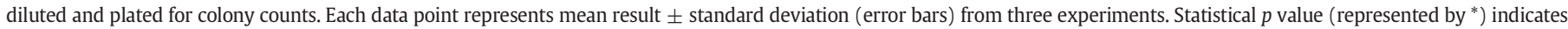
concentrations that are significantly different from control. ${ }^{*} p<0.05$.

of them derives from plants, and then are synthetized in large scale. For example, Pendota, Aderogba, Ndhlala, \& Staden (2013) evaluated the antifungal potential of Buddleja salviifolia (L.) Lam. leaf extracts and its isolated compounds, and observed that MIC values obtained for hexane,

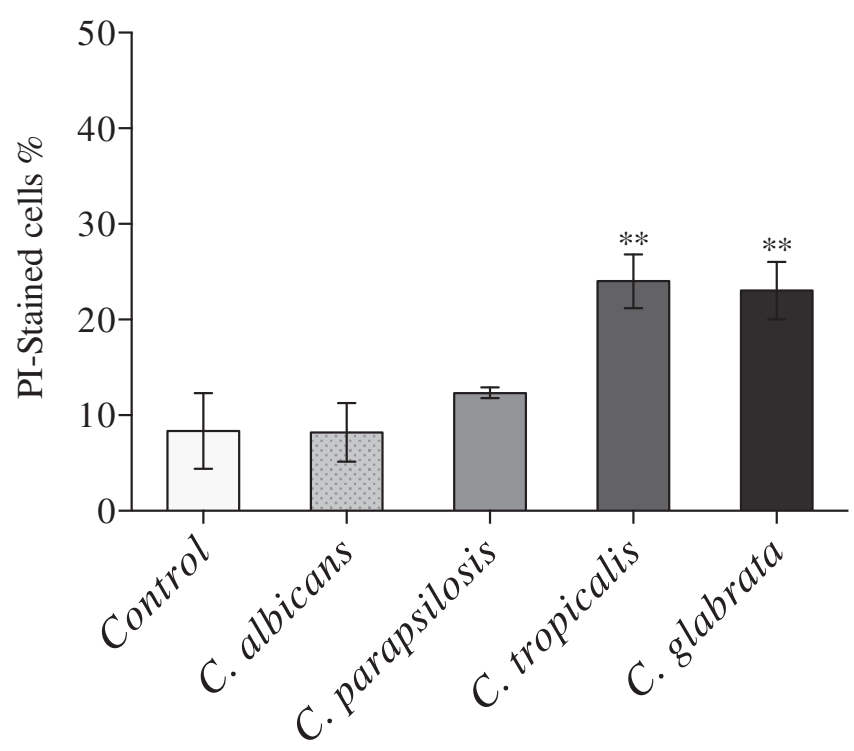

Fig. 3. Effect of the $H$. androsaemum ethanol:water extract on the Candida species membrane. The percentage of PI-stained cells was analyzed by flow cytometry with and without exposure to $H$. androsaemum extracts for a period of $4 \mathrm{~h}$. Statistical $p$ value (represented by ${ }^{* *}$ ) indicates concentrations that are significantly different from control. ${ }^{*} p<0.01$. dichloromethane, ethyl acetate and butanol extracts, as also for individual compounds were higher than those obtained for the positive control. However, the obtained MIC values for the individual compounds were lower than those for the whole extracts (Pendota et al., 2013). It means that a wide variety of metabolic and biochemical reactions may occurs between the different phytochemicals present in natural matrices, some of them improving the final biological effect while other ones exert an antagonistic effect.

\subsection{Phenolic compounds}

The chromatographic profile of the $H$. androsaemum ethanol:water extract recorded at $280 \mathrm{~nm}$ is shown in Fig. 5, and peak characteristics, tentative identities and phenolic compounds quantification are presented in Table 2. Compounds 2 (protocatechuic acid), 4 (5-O-caffeoylquinic acid), 6 (epicatechin), 11 (taxifolin), 12 (quercetin-3-0-glucuronide) and 13 (quercetin-3-0-glucoside) were positively identified by comparison with authentic standards, as also by their MS fragmentation pattern, retention time and UV-vis characteristics. 5-O-Caffeoylquinic acid and quercetin derivatives have been reported in methanol extracts from the aerial parts (Rainha et al., 2011) and leaves (Porzel et al., 2014; Valentão et al., 2003) of $H$. androsaemum, and in aqueous extracts from the leaves (Valentão et al., 2002; Valentão et al., 2004).

Compound $1\left([\mathrm{M}-\mathrm{H}]^{-}\right.$at $\left.\mathrm{m} / \mathrm{z} 353\right)$ was identified as $3-0$ caffeoylquinic acid based on its fragmentation pattern, yielding a base peak at $m / z 191$ (deprotonated quinic acid) and an ion at $m / z 179$ [caffeic acid-H] $]^{-}$with an intensity of $47 \%$ of the base peak, as reported by Clifford, Johnston, Knight and Kuhnert (2005, 2003), and Clifford, Johnston, Knight, and Kuhnert (2003). Similarly, compound 3 ([M-H] ${ }^{-}$ at $m / z$ 337) was tentatively identified according to its $\mathrm{MS}^{2}$ fragmentation as 3-O-p-coumaroylquinic acid (Clifford et al., 2003; Clifford et al., 


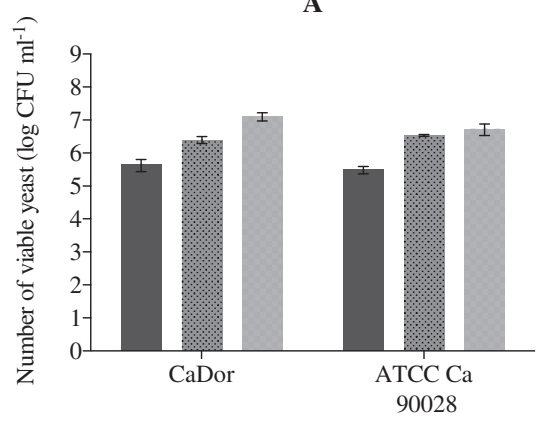

C

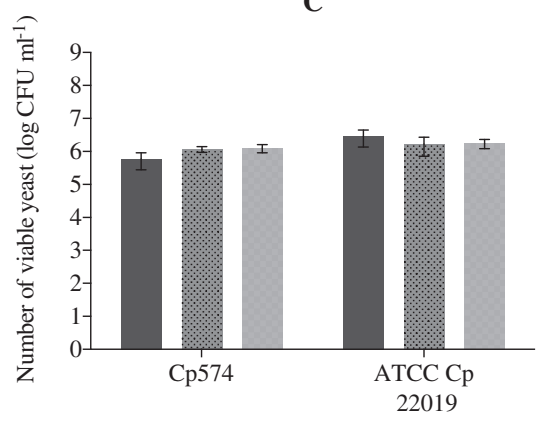

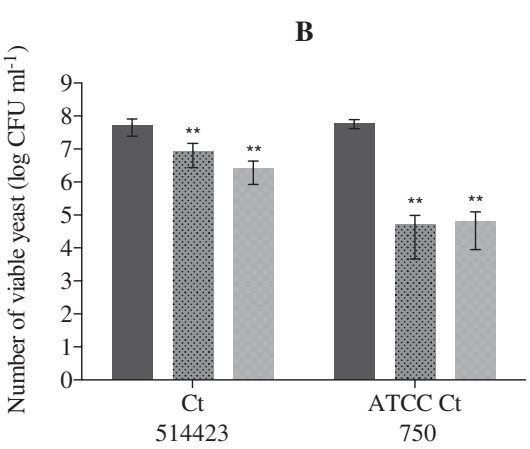

D

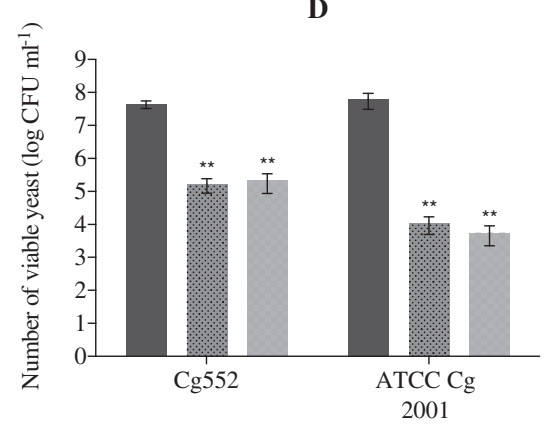

Control

$12.5 \mathrm{mg} / \mathrm{ml}$

$25 \mathrm{mg} / \mathrm{ml}$

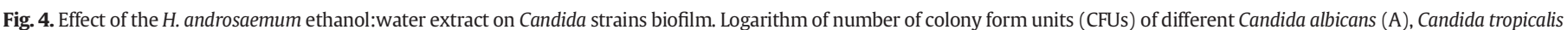

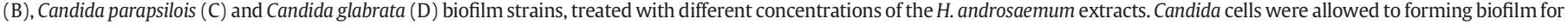

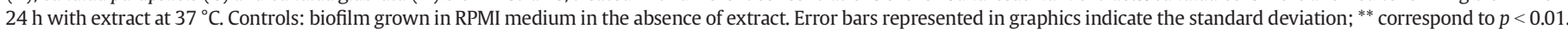

2005). These compounds have been already reported in aqueous (Valentão et al., 2002; Valentão et al., 2004) and methanolic (Porzel et al., 2014; Valentão et al., 2003) extracts from leaves and in aerial parts (Rainha et al., 2011) of $H$. androsaemum.

Compounds 5, 7, 8 and 10 showed UV spectra with $\lambda_{\max } 280 \mathrm{~nm}$, characteristic of proanthocyanidins. Peaks 5 and 10 presented pseudomolecular ions corresponding to (epi)catechin dimers $\left([\mathrm{M}-\mathrm{H}]^{-}\right.$ at $m / z 577)$ and compounds $7\left([\mathrm{M}-\mathrm{H}]^{-}\right.$at $m / z$ 865) and $8\left([\mathrm{M}-\mathrm{H}]^{-}\right.$at $\mathrm{m} / \mathrm{z} 1153$ ) to a trimer and a tetramer, respectively. The positive identification in the extract of epicatechin as the only flavan-3-ol monomer would suggest an epicatechin-based identity for those peaks. Thus, the compounds might correspond to the B-linked epicatechin series, i.e., procyanidin dimer B2 (epicatechin-4,8-epicatechin, peak 5), trimer $\mathrm{C} 1$

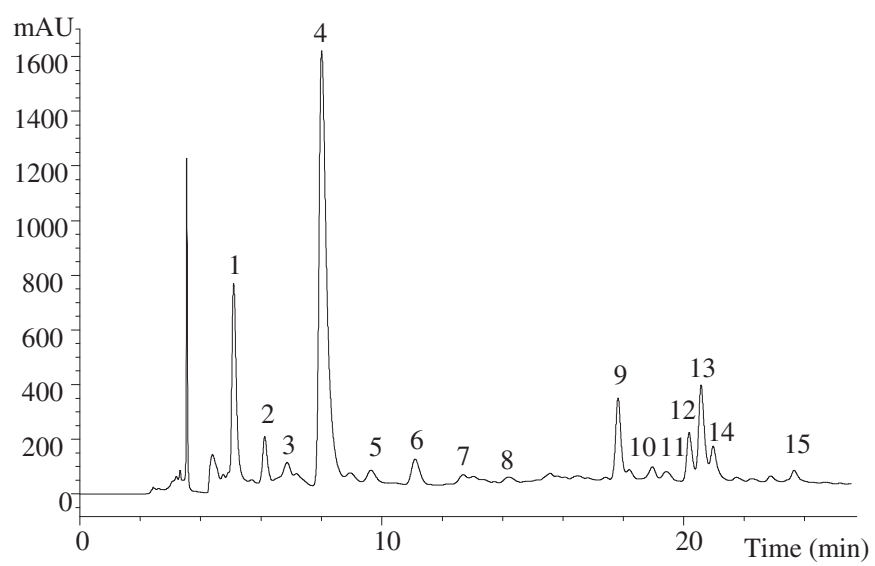

Fig. 5. Phenolic compounds profile of the H. androsaemum ethanol:water extract recorded at $280 \mathrm{~nm}$. (epicatechin-4,8-epicatechin-4,8-epicatechin, peak 7) and the (4,8)linked epicatechin tetramer (peak 8), whereas the late elution of peak 10 suggests a $(4,6)$ linkage (i.e., epicatechin-4,6-epicatechin; dimer B5). These identities would also be coherent with their expected relative order of elution (Santos-Buelga, García-Viguera, \& TomásBarberán, 2003). This identification differs from the one recently reported by Ramalhete et al. (2016), who indicated the presence of (+)-catechin and related proanthocyanidins in methanol extracts obtained from the aerial parts of this plant.

Compounds $14\left([\mathrm{M}-\mathrm{H}]^{-}\right.$at $\left.m / z 463\right)$ and $15\left([\mathrm{M}-\mathrm{H}]^{-}\right.$at $\left.m / z 433\right)$ presented UV spectra $\left(\lambda_{\max } 354-356 \mathrm{~nm}\right)$ and the production of a unique fragment ion at $m / z 301$ ([quercetin- $\left.\mathrm{H}]^{-}\right)$, which allowed their identification as quercetin- $O$-hexoside and quercetin- $O$-pentoside, respectively. Finally, compound $9\left([\mathrm{M}-\mathrm{H}]^{-}\right.$at $m / z$ 449) was tentatively identified as eriodictyol- $O$-hexoside, based on its UV spectrum and the product ion observed at $m / z 287$. No further conclusion about the nature and position of the substituting sugar of these compounds can be made from the obtained LC-DAD-MS data. Similar quercetin glycosides have been indicated in aqueous (Valentão et al., 2002; Valentão et al., 2004) and methanol (Porzel et al., 2014; Rainha et al., 2011; Valentão et al., 2003) preparations of the plant, whereas, to the author's best knowledge, the presence of eriodictyol-O-hexoside has not been previously reported.

Overall, 5-O-caffeoylquinic acid followed by 3-O-caffeoylquinic acid were the majority phenolic compounds present in the $H$. androsaemum ethanol:water extract, and they should account for the observed antioxidant, cytotoxic, anti-inflammatory and anti-Candida activities.

\section{Acknowledgements}

The authors thank the Foundation for Science and Technology (FCT, Portugal) and FEDER under Programme PT2020 for financial support to CIMO (UID/AGR/00690/2013), LSRE (Project UID/EQU/50020/2013), N. 
Table 2

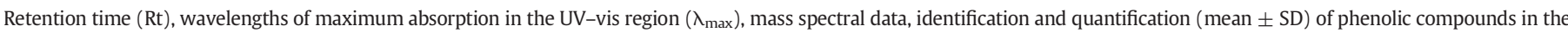
H. androsaemum ethanol:water extract.

\begin{tabular}{|c|c|c|c|c|c|c|}
\hline Compound & $\begin{array}{l}\mathrm{Rt} \\
(\mathrm{min})\end{array}$ & $\begin{array}{l}\lambda_{\max } \\
(\mathrm{nm})\end{array}$ & $\begin{array}{l}\text { Pseudomolecular ion } \\
{[\mathrm{M}-\mathrm{H}]^{-}(\mathrm{m} / \mathrm{z})}\end{array}$ & $\operatorname{MS}^{2}(m / z)$ & Tentative identification & $\begin{array}{l}\text { Quantification } \\
\text { (mg/g extract) }\end{array}$ \\
\hline 1 & 5.1 & 328 & 353 & 191(100),179(47),161(5),135(38) & 3-O-Caffeoylquinic acid & $11.6 \pm 0.1$ \\
\hline 2 & 6.1 & 260,294 sh & 153 & $109(100)$ & Protocatechuic acid & $4.29 \pm 0.001$ \\
\hline 3 & 6.9 & 312 & 337 & $191(25), 173(10), 163(100), 119(65)$ & 3-O-p-Coumaroylquinic acid & $0.88 \pm 0.01$ \\
\hline 4 & 8.0 & 328 & 353 & $191(100), 179(3), 161(6), 135(4)$ & 5-O-Caffeoylquinic acid & $40.1 \pm 0.1$ \\
\hline 5 & 9.0 & 280 & 577 & $451(25), 425(50), 407(100), 289(63), 287(8)$ & Procyanidin B2 & $5.6 \pm 0.1$ \\
\hline 6 & 11.1 & 280 & 289 & $245(18), 203(11), 187(4), 161(7), 137(8)$ & (-)-Epicatechin & $6.9 \pm 0.2$ \\
\hline 7 & 13.1 & 280 & 865 & $739(4), 713(3), 577(8), 575(4), 425(19), 407(20), 289(23), 287(8)$ & Procyanidin $C 1$ & $3.4 \pm 0.2$ \\
\hline 8 & 14.2 & 280 & 1153 & $865(9), 863(12), 577(25), 575(42), 289(5), 287(9)$ & Epicatechin tetramer & $4.4 \pm 0.2$ \\
\hline 9 & 17.9 & $286,336 \mathrm{sh}$ & 449 & $287(100)$ & Eriodictyol-O-glucoside & $3.7 \pm 0.2$ \\
\hline 10 & 19.0 & 280 & 577 & $451(67), 425(61), 407(100), 289(82), 287(14)$ & Procyanidin B5 & $4.8 \pm 0.4$ \\
\hline 11 & 19.4 & 288,340 sh & 303 & $285(100), 199(12), 177(8), 150(15), 125(35)$ & Taxifolin & $3.4 \pm 0.1$ \\
\hline 12 & 20.2 & 350 & 477 & $301(100)$ & Quercetin-3-0-glucuronide & $4.71 \pm 0.01$ \\
\hline 13 & 20.6 & 354 & 463 & $301(100)$ & Quercetin-3-O-glucoside & $10.69 \pm 0.02$ \\
\hline 14 & 21.0 & 354 & 463 & $301(100)$ & Quercetin-O-hexoside & $4.41 \pm 0.04$ \\
\hline \multirow[t]{4}{*}{15} & 23.7 & 356 & 433 & $301(100)$ & Quercetin-O-pentoside & $1.33 \pm 0.02$ \\
\hline & & & & & Total phenolic acid derivatives & $56.9 \pm 0.2$ \\
\hline & & & & & Total flavonoids & $53 \pm 1$ \\
\hline & & & & & Total phenolic compounds & $110 \pm 0.4$ \\
\hline
\end{tabular}

Extraction yield: $33 \%$. sh - shoulder.

Martins (SFRH/BD/87658/2012), S. Silva (SFRH/BPD/109053/2015) and L. Barros (SFRH/BPD/107855/2015) grants. The authors would also like to thank Coordenação de Aperfeiçoamento de Pessoal de Nível Superior (CAPES), Conselho Nacional de Desenvolvimento Científico e Tecnológico (Cnpq), and Fundação Araucária for the financial support received. Flávia Tobaldini-Valerio, acknowledge the financial support of CAPES - Proc. 9469/14-1. The authors also thank FCT for the Strategic Project of the UID/BIO/04469/2013 unit, FCT and European Union funds (FEDER/COMPETE) for the project RECI/BBB-EBI/0179/2012 (FCOMP01-0124-FEDER-027462).

\section{References}

Abreu, R. M. V., Ferreira, I. C. F. R., Calhelha, R. C., Lima, R. T., Vasconcelos, M. H., Adega, F., ... Queiroz, M. J. R. P. (2011). Anti-hepatocellular carcinoma activity using human HepG2 cells and hepatotoxicity of 6-substituted methyl 3- aminothieno [3,2-b] pyridine-2carboxylate derivatives: In vitro evaluation, cell cycle analysis and QSAR studies. European Journal of Medicinal Chemistry, 46, 5800-5806.

Alves, C. T., Ferreira, I. C. F. R., Barros, L., Silva, S., Azeredo, J., \& Henriques, M. (2014). Antifungal activity of phenolic compounds identified in flowers from north eastern Portugal against Candida species. Future Microbiology, 9(2), 139-146.

Aruoma, O. I. (2003). Methodological considerations for characterizing potential antioxidant actions of bioactive components in plant foods. Mutation Research - Fundamental and Molecular Mechanisms of Mutagenesis, 523-524, 9-20. http://dx.doi.org/10.1016/S00275107(02)00317-2.

Azevedo, M. M., Ramalho, P., Silva, A. P., Teixeira-Santos, R., Pina-Vaz, C., \& Rodrigues, A. G. (2014). Polyethyleneimine and polyethyleneimine-based nanoparticles: Novel bacterial and yeast biofilm inhibitors. Journal of Medical Microbiology, 63(pt9), 1167-1173.

Barros, L., Dueñas, M., Dias, M. I., Sousa, M. J., Santos-Buelga, C., \& Ferreira, I. C. F. R. (2012). Phenolic profiles of in vivo and in vitro grown Coriandrum sativum L. Food Chemistry, 132(2), 841-848. http://dx.doi.org/10.1016/j.foodchem.2011.11.048.

Carocho, M. \& Ferreira, I. C. F. R. (2013). A review on antioxidants, prooxidants and related controversy: Natural and synthetic compounds, screening and analysis methodologies and future perspectives. Food and Chemical Toxicology, 51, 15-25. http://dx.doi.org/10.1016/j.fct. 2012.09.021.

Chandra, J., Kuhn, D. M., Mukherjee, P. K., Hoyer, L. L., McCormick, T., \& Ghannoum, M. A. (2001) Biofilm formation by the fungal pathogen Candida albicans: Development, architecture, and drug resistance. Journal of Bacteriology, 183(18), 5385-5394.

Chen, L., \& Kang, Y. -H. (2013). Anti-inflammatory and antioxidant activities of red pepper (Capsicum annuum L.) stalk extracts: Comparison of pericarp and placenta extracts. Journal of Functional Foods, 5(4), 1724-1731. http://dx.doi.org/10.1016/j.jff.2013.07.018.

Clifford, M. N., Johnston, K. L., Knight, S., \& Kuhnert, N. (2003). Hierarchical scheme for LC-MSn identification of chlorogenic acids. Journal of Agricultural and Food Chemistry, 51(10), 2900-2911. http://dx.doi.org/10.1021/jf026187q.

Clifford, M. N., Johnston, K. L., Knight, S., \& Kuhnert, N. A. (2005). Discriminating between the six isomers of dicaffeoylquinic acid by LC-MSn. Journal of Agricultural and Food Chemistry, 53, $3821-3832$.

Clinical and Laboratory Standards Institute (2008). In P. A. Wayne (Ed.), M27-A3, Reference method for broth dilution antifungal susceptibility testing of yeasts: approved standard (3rd ed.)

Correia, H., González-Paramás, A., Amaral, M. T., Santos-Buelga, C., \& Batista, M. T. (2005). Characterization of polyphenols by HPLC-PAD-ESI/MS and antioxidant activity in Equisetum telmateia. Phytochemical Analysis, 16(5), 380-387. http://dx.doi.org/10.1002/pca.864.
Dalben-Dota, K. F., Faria, M. G. I., Bruschi, M. L., Pelloso, S. M., Lopes-Consolaro, M. E., \& Svidzinski, T. I. E. (2010). Antifungal activity of propolis extract against yeasts isolated from vaginal exudates. Journal of Alternative and Complementary Medicine, 16(3), 285-290.

Dato, S., Crocco, P., D'Aquila, P., Rango, F., Bellizzi, D., Rose, G., \& Passarino, G. (2013). Exploring the role of genetic variability and lifestyle in oxidative stress response for healthy aging and longevity. International Journal of Molecular Sciences, 14(8), 16443-16472. http://dx.doi.org/ 10.3390/ijms140816443.

Douglas, L. J. (2003). Candida biofilms and their role in infection. Trends in Microbiology, 11 30-36.

Espín, J. C., García-Conesa, M. T., \& Tomás-Barberán, F. A. (2007). Nutraceuticals: Facts and fiction. Phytochemistry, 68(22-24), 2986-3008. http://dx.doi.org/10.1016/j.phytochem.2007. 09.014.

Estivill, D., Arias, A., Torres-Lana, A., Carrillo-Munoz, A. J., \& Arevalo, M. P. (2011). Biofilm formation by five species of Candida on three clinical materials. Journal of Microbiological Methods, 86(2), 238-242.

Fernandez-Panchon, M. S., Villano, D., Troncoso, A. M., \& Garcia-Parrilla, M. C. (2008). Antioxidant activity of phenolic compounds: From in vitro results to in vivo evidence. Critical Reviews in Food Science and Nutrition, 48(7), 649-671. http://dx.doi.org/10.1080/ 10408390701761845

Gacser, A., Schafer, W., Nosanchuk, J. S., Salomon, S., \& Nosanchuk, J. D. (2007). Virulence of Candida parapsilosis, Candida orthopsilosis, and Candida metapsilosis in reconstituted human tissuemodels. Fungal Genetics and Biology, 44, 1336-1341.

Ganguly, S., \& Mitchell, A. P. (2011). Mucosal biofilms of Candida albicans. Current Opinion in Microbiology, 14, 380-385.

Guedes, A. P., Amorim, L. R., Vicente, A. M. S., Ramos, G., \& Fernandes-Ferreira, M. (2003). Essential oils from plants and in vitro shoots of Hypericum androsaemum L. Journal of Agricultural and Food Chemistry, 51(5), 1399-1404. http://dx.doi.org/10.1021/jf020872f.

Guinea, J. (2014). Global trends in the distribution of Candida species causing candidemia. Clinical Microbiology and Infection, 20(Suppl 6), 5-10.

Halliwell, B. (2012). Free radicals and antioxidants: Updating a personal view. Nutrition Reviews, 70(5), 257-265. http://dx.doi.org/10.1111/j.1753-4887.2012.00476.x.

Hernandez, M. F., Falé, P. L. V., Araújo, M. E. M., \& Serralheiro, M. L. M. (2010). Acetylcholinesterase inhibition and antioxidant activity of the water extracts of several Hypericum species. Food Chemistry, 120(4), 1076-1082. http://dx.doi.org/10.1016/j.foodchem.2009.11.055.

Khan, M. S., Ahmad, I., Cameotra, S. S., \& Botha, F. (2014). Sub-MICs of Carum copticum and Thymus vulgaris influence virulence factors and biofilm formation in Candida spp. BMC Complementary and Alternative Medicine, 14(1), 337.

Klepser, M. E., Wolfe, E. J. Jones, R. N., \& Nightingale, C. H. (1997). Antifungal pharmacodynamic characteristics of fluconazole and amphotericin B tested against A Candida albicans. Antimicrobial Agents and Chemotherapy, 41(6), 1392-1395.

Kuhn, D. M., Chandra, J., Mukherjee, P. K., \& Ghannoum, M. A. (2002). Comparison of biofilms formed by Candida albicans and Candida parapsilosis on bioprosthetic surfaces. Infection and Immunity, 70, 878-888

Lewis, K. (2007). Persister cells, dormancy and infectious disease. Nature Reviews Microbiology, $5,48-56$

Li, A., Li, S., Zhang, Y., Xu, X., Chen, Y., \& Li, H. (2014). Resources and biological activities of natural polyphenols. Nutrients, 6, 6020-6047. http://dx.doi.org/10.3390/nu6126020.

Lott, T. J., Fundyga, R. E., Kuykendall, R. J., \& Arnold, J. (2005). The human commensal yeast, Candida albicans, has an ancient origin. Fungal Genetics and Biology, 42(5), 444-451. http://dx. doi.org/10.1016/j.fgb.2005.01.012.

Martins, N., Barros, L., Dueñas, M., Santos-Buelga, C., \& Ferreira, I. C. F. R. (2015). Characterization of phenolic compounds and antioxidant properties of Glycyrrhiza glabra L. rhizomes and roots. RSC Advances, 5(34), 26991-26997. http://dx.doi.org/10.1039/C5RA03963K.

Mazandarani, M., Yassaghi, S., Rezaei, M. B., Mansourian, A. R., \& Ghaemi, E. O. (2007). Ethnobotany and antibacterial activities of two endemic species of Hypericum in north-east of Iran. Asian Journal of Plant Sciences, 6(2), 354-358.

Moran, C., Grussemeyer, C. A., Spalding, J. R., Benjamin, D. K. J., \& Reed, S. D. (2010). Comparison of costs, length of stay, and mortality associated with Candida glabrata and Candida albicans bloodstream infections. American Journal of Infection Control, 38, 78-80. 
Murray, M. T. (2004). In Gramercy Books (Ed.), The healing power of herbs (2nd ed.). New York, NY: Random House.

Nogueira, T., Medeiros, M. A., Marcelo-Curto, M. J., García-Pérez, B. E., Luna-Herrera, J., \& Costa, M. C. (2013). Profile of antimicrobial potential of fifteen Hypericum species from Portugal. Industrial Crops and Products, 47, 126-131. http://dx.doi.org/10.1016/j.indcrop.2013.03.005.

Pendota, S. C. Aderogba, M. A., Ndhlala, A. R. \& Staden, J. V. (2013). Antimicrobial and acetylcholinesterase inhibitory activities of Buddleja salviifolia (L.) Lam. leaf extracts and isolated compounds. Journal of Ethnopharmacology, 148(2), 515-520. http://dx.doi.org/10.1016/j. jep.2013.04.047.

Pina-Vaz, C., Sansonetty, F., Rodrigues, A. G., Costa-Oliveira, S., Tavares, C., \& Martinez-deOliveira, J. (2001). Cytometric approach for rapid evaluation of susceptibility of Candida strains to antifungals. Clinical Microbiology and Infection, 7, 609-618.

Porzel, A., Farag, M. A., Mülbradt, J., \& Wessjohann, L. A. (2014). Metabolite profiling and fingerprinting of Hypericum species: A comparison of MS and NMR metabolomics. Metabolomics, 10(4), 574-588. http://dx.doi.org/10.1007/s11306-013-0609-7.

Rainha, N., Lima, E., \& Baptista, J. (2011). Comparison of the endemic Azorean Hypericum foliosum with other Hypericum species: Antioxidant activity and phenolic profile. Natural Product Research, 25(February 2015), 123-135. http://dx.doi.org/10.1080/14786419.2010. 512560.

Ramage, G., Mowat, E., Jones, B., Williams, C., \& Lopez-Ribot, J. (2009). Our current understanding of fungal biofilms. Critical Reviews in Microbiology, 35, 340-355.

Ramalhete, N., Machado, A., Serrano, R., Gomes, E. T., Mota-Filipe, H., \& Silva, O. (2016). Comparative study on the in vivo antidepressant activities of the Portuguese Hypericum foliosum Hypericum androsaemum and Hypericum perforatum medicinal plants. Industrial Crops and Products, 82, 29-36. http://dx.doi.org/10.1016/j.indcrop.2015.12.014.

Ramos, A. A., Marques, F., Fernandes-Ferreira, M., \& Pereira-Wilson, C. (2013). Water extracts of tree Hypericum sps. protect DNA from oxidative and alkylating damage and enhance DNA repair in colon cells. Food and Chemical Toxicology, 51, 80-86. http://dx.doi.org/10.1016/j. fct.2012.09.014.

Santos-Buelga, C., García-Viguera, C., \& Tomás-Barberán, F. A. (2003). On-line identification of flavonoids by HPLC coupled to diode array detection. In C. Santos-Buelga, \& G.
Williamson (Eds.), Methods in polyphenol analysis (pp. 92-127). Cambridge, UK: Royal Society of Chemistry.

Silva, S., Negri, M., Henriques, M., Oliveira, R., Williams, D. W., \& Azeredo, J. (2012). Candida glabrata, Candida parapsilosis and Candida tropicalis: Biology, epidemiology, pathogenicity and antifungal resistance. FEMS Microbiology Reviews, 36(2), 288-305.

Soobrattee, M. A. Neergheen, V. S. Luximon-Ramma, A. Aruoma, O. I. \& Bahorun, T. (2005). Phenolics as potential antioxidant therapeutic agents: Mechanism and actions. Mutation Research - Fundamental and Molecular Mechanisms of Mutagenesis, 579(1-2), 200-213. http://dx.doi.org/10.1016/j.mrfmmm.2005.03.023.

Valentão, P., Fernandes, E., Carvalho, F., Andrade, P. B., Seabra, R. M., \& Bastos, M. L. (2002). Antioxidant activity of Hypericum androsaemum infusion: Scavenging activity against superoxide radical, hydroxyl radical and hypochlorous acid. Biological \& Pharmaceutical Bulletin, 25(10), 1320-1323. http://dx.doi.org/10.1248/bpb.25.1320.

Valentão, P., Dias, A., Ferreira, M., Silva, B., Andrade, P. B., Bastos, M. L., \& Seabra, R. M. (2003). Variability in phenolic composition of Hypericum androsaemum. Natural Product Research, 17(2), 135-140. http://dx.doi.org/10.1080/1057563021000060149.

Valentão, P., Carvalho, M., Fernandes, E., Carvalho, F., Andrade, P. B., Seabra, R. M., \& de Lourdes Bastos, M. (2004). Protective activity of Hypericum androsaemum infusion against tert-butyl hydroperoxide-induced oxidative damage in isolated rat hepatocytes. Journal of Ethnopharmacology, 92(1), 79-84. http://dx.doi.org/10.1016/j.jep.2004.02.004.

Valko, M., Leibfritz, D., Moncol, J., Cronin, M. T. D., Mazur, M., \& Telser, J. (2007). Free radicals and antioxidants in normal physiological functions and human disease. The International Journal of Biochemistry \&' Cell Biology, 39(1), 44-84. http://dx.doi.org/10.1016/j.biocel.2006.07.001.

Xavier, C. P. R., Lima, C. F., Fernandes-Ferreira, M. \& Pereira-Wilson, C. (2012). Hypericum androsaemum water extract inhibits proliferation in human colorectal cancer cells through effects on MAP kinases and PI3K/Akt pathway. Food E' Function, 3, 844. http://dx.doi.org/10. 1039/c2fo10226a. 